\title{
Novas formas de leitura e escrita na era da mobilidade: reflexões em torno da arte locativa
}

\author{
Edgar Roberto Kirchof" \\ Andrea da Cunha Russo***
}

\section{Resumo}

O presente artigo propõe uma reflexão sobre novas formas de leitura e escrita na era da mobilidade, tomando como objeto de análise alguns projetos artísticos e literários realizados com mídias locativas. As análises baseiam-se em pesquisa bibliográfica, de um lado, e, de outro, em uma experiência de interação realizada com a obra Arquitetura Móvel, da artista brasileira Karolina Ziulkosky, durante quatro dias, de 8 a 12 de dezembro de 2016, na Avenida Paulista. O artigo está estruturado em três seções. Após uma breve introdução, são expostos e discutidos os conceitos teóricos que embasam as análises da obra Arquitetura Móvel, as quais são apresentadas na seção seguinte. Alguns dos principais pesquisadores que fundamentam as reflexões e as análises propostas são Drew Hemment, André Lemos, Adriana de Souza e Silva, Marc Tuters, Kazys Varnelis, Howard Rheingold, Kahterine Hayles, Malcolm McCullough.

Palavras-chave: Arte locativa. Arquitetura Móvel. Mídias locativas. Narrativas locativas.

\section{Introdução}

Vários projetos realizados com arte locativa, mesmo antes do uso generalizado de aparelhos celulares de última geração, envolviam práticas de leitura,

Graduado em Letras (Português/Alemão) pela Universidade do Vale do Rio dos Sinos (1995). Graduado em Teologia pela Escola Superior de Teologia (1998). Mestre em Ciências da Comunicação pela Universidade do Vale do Rio dos Sinos (1997). Doutor em Linguística e Letras pela Pontifícia Universidade Católica do Rio Grande do Sul (2001), tendo realizado um pós-doutorado na área da Biossemiótica na Universidade de Kassel, Alemanha. Atualmente, é professor adjunto da Universidade Luterana do Brasil, atuando, como docente e pesquisador, no PPGEDU e no Curso de Letras. Tem experiência na área de Letras e Educação, atuando principalmente nos seguintes temas: Teoria da Literatura, Estudos Culturais, Semiótica e Cibercultura.E-mail: ekirchof@hotmail.com

* Graduada em Comunicação Social pela Pontifícia Universidade Católica do Rio Grande do Sul (1994). Especialista em História da Arte, tendo concluído o curso Teoria e Crítica pela Universidade de Belas Artes de São Paulo (2014), além de também ter finalizado uma especialização em Comunicação e Semiótica nessa mesma universidade. Em 2015, concluiu o mestrado em Educação e Estudos Culturais na Universidade Luterana do Brasil. E-mail: andrearussors@gmail.com

Data de submissão: 27/07/2017 - Data de aceite: ago. 2017 http://dx.doi.org/10.5335/rdes.v13i2.7254 
escrita e audição de textos verbais, o que levou pesquisadores como Nancy Katherine Hayles (2008), entre outros, a considerar tais projetos como pertencentes ao campo da literatura digital, muito embora grande parte da crítica os classifique a partir do campo da arte locativa ou da arte com mídias locativas (HEMMENT, 2006). Após a popularização dos smartphones equipados com internet sem fio e tecnologia de geolocalização, práticas de fruição, escrita e leitura com base em geolocalização deixaram de ser realizadas apenas no campo artístico-literário, tornando-se cada vez mais comuns também entre grandes públicos, o que ocorreu devido ao uso massivo de aplicativos que permitem não apenas ler objetos e locais a partir de coordenadas espaciais como também escrever textos que se agregam continuamente aos demais textos já disponíveis nos locais de anotação. Em poucos termos, o uso de aplicativos com geolocalização, nos últimos anos, tem estimulado uma produção intensa de formas textuais baseadas em localidade, agregando camadas textuais que se acumulam umas sobre as outras em contínua expansão.

Diante desse contexto, o presente artigo propõe uma reflexão sobre novas formas de leitura e escrita na era da mobilidade, tomando como objeto de análise alguns projetos artísticos e literários realizados com mídias locativas, com ênfase na obra Arquitetura Móvel, da artista brasileira Karolina Ziulkosky. Alguns dos principais pesquisadores que fundamentam o referencial teórico das análises aqui apresentadas são Drew Hemment, André Lemos, Adriana de Souza e Silva, Marc Tuters, Kazys Varnelis, Howard Rheingold, Kahterine Hayles, Malcolm McCullough, entre outros. As análises baseiam-se, de um lado, em pesquisa bibliográfica e, de outro, em uma experiência de interação realizada com a obra Arquitetura Móvel, durante quatro dias, de 8 a 12 de dezembro de 2016, na Avenida Paulista, sendo que os percursos realizados como proposta do aplicativo foram feitos a pé. As interações foram realizadas durante as tardes de sábado e domingo, a fim de evitar o grande fluxo de pessoas, comum àquele ambiente em dias úteis. Assim sendo, as imagens utilizadas neste artigo são, em parte, recortes do vídeo de divulgação do aplicativo e, em parte, capturas de tela realizadas ao longo da experiência de interação com a obra.

$\mathrm{O}$ artigo está estruturado em quatro seções. Após esta breve introdução, são expostos e discutidos alguns conceitos teóricos, como mídias locativas, serviços com base de localização, arte locativa e narrativas locativas. Também se apresenta, nesta mesma seção, uma reflexão sobre novas formas de textualidade e práticas de escrita e leitura proporcionadas pelas mídias locativas. Por fim, o artigo contém uma seção com a análise da obra Arquitetura Móvel, tomando como referência sua proposta poética, suas potencialidades tecnológicas e as suas formas de leitura e escrita, na qual se encontram também as considerações finais. 


\section{Experimentos e projetos artístico-literários com mídias locativas}

André Lemos (2007) define as mídias locativas (em inglês, locative media) como "um conjunto de tecnologias e processos info-comunicacionais cujo conteúdo informacional vincula-se a um lugar específico" (2007, p. 1). Como esclarece o autor, o termo foi proposto em 2003 por Karlis Kalnins, no RIXC - Center for New Media, com a finalidade de distinguir as explorações criativas (as quais são denominadas mídias locativas) do uso coorporativo desse tipo de tecnologia (cujas criações geralmente são denominadas de "serviços com base de localização" [location-based services]). Mídias locativas já existiam mesmo antes do surgimento das tecnologias digitais, pois a informação veiculada por signos como placas de trânsito, por exemplo, só faz sentido porque a placa está inserida em algum lugar específico. No entanto, com o surgimento das tecnologias digitais, as mídias locativas se tornaram dinâmicas, interativas e, consequentemente, mais complexas.

Essa mudança ocorreu, inicialmente, devido à popularização dos aparelhos móveis, da internet sem fio (wireless) e, mais recentemente, também, da tecnologia de geolocalização. A partir de então, na era das mídias locativas digitais, o conteúdo é processado através de redes sem fio (Wi-Fi, Wi-Max, Bluetooth), por dispositivos eletrônicos móveis (tablets, telefones celulares, aparelhos de GPS), os quais coletam, processam e permitem produzir dados e mensagens levando em conta a localização do usuário. É necessário enfatizar, contudo, que o funcionamento da mídia locativa na era digital pressupõe mais do que apenas o uso de aparelhos móveis com tecnologias sem fio (wireless) ou de geolocalização: é necessária uma verdadeira articulação entre a informação (buscada, recebida ou produzida), o lugar e o dispositivo.

No campo das artes e da literatura, projetos e obras cujo conceito poético envolve a localidade e a movimentação de sujeitos fruidores/leitores através do entorno já eram realizados muito antes do surgimento das tecnologias digitais. Como observa Drew Hemment,

[...] toda a arte está vinculada à localização, em certo grau, mesmo na medida em que ela responde ao espaço criado pela galeria e pela moldura, ou se o objeto encontrado está marcado pela ausência da localização de onde ele foi retirado (2006, p. 349).

Em formas artísticas como a escultura, as performances e a instalação, a importância do espaço de ocorrência da obra para a experiência da fruição é bastante evidente. Já para artistas como Richard Long e Robert Smithson - que, no final da década de 1960, foram identificados com o movimento Land Art -, a localização fazia parte do próprio conceito poético das suas obras, o que revela um uso intencional do lugar como elemento que agrega sentidos e efeitos estéticos ao fazer artístico. Por essa razão, tais artistas poderiam ser considerados como 
precursores das artes locativas - termo utilizado por Drew Hemment (2006) - ou das obras que envolvem experiências de mobilidade, conforme prefere Teri Rueb (2004, p. 221).

Além disso, também é possível buscar os antecessores das artes com mídia locativa antes mesmo da Land Art, pois, como observa André Lemos, já os situacionistas, dadaístas e surrealistas incorporavam noções de localidade a seus projetos poéticos:

Enquanto os situacionistas, dadaístas e surrealistas buscavam, pela deriva e criação de situações, transformar a vivência urbana, enquanto o flâneur se encantava com as passagens e florestas de signos da modernidade, hoje as práticas artísticas e/ ou ativistas com as mídias locativas buscam a mesma coisa: apropriação e transformação do espaço urbano (2007, p. 13).

Com o desenvolvimento das mídias eletrônicas, os projetos artísticos de mobilidade passaram a incorporar, primeiro, o uso de aparelhos como rádio e telefone e, mais tarde, foram sendo incorporadas também as inovações proporcionadas pela tecnologia digital, tais como o correio eletrônico e as chamadas através de telefones móveis. No entanto, projetos artísticos com uso de smartphones equipados com GPS e rede sem fio são muito recentes. Segundo Marc Tuters e Kazys Varnelis (2006, p. 357), esse tipo de arte locativa emergiu apenas ao longo da última década como resposta às experiências incorpóreas e presas às telas de computador que predominavam na net.art até então. Visando ultrapassar essas supostas limitações, os projetos mais recentes de arte locativa demarcam, como território, o mundo para além das galerias dos museus e também das telas dos computadores.

A partir de uma reflexão sobre projetos considerados representativos da arte locativa - muitos dos quais foram executados ainda no final dos anos 1990 e início dos anos 2000, quando nem os smartphones e tampouco a tecnologia de GPS estavam disseminados entre grandes camadas da população mundial -, Hemment (2006) cita artistas como Masaki Fujihata (Japão), Teri Rueb (Canadá) e Stefan Schemat (Alemanha) como precursores desse campo e sugere uma classificação preliminar das manifestações de arte locativa a partir de três categorias: projetos de mapeamento, projetos de geoanotação e projetos ambulantes (que pressupõem deriva e deslocamento) (HEMMENT, 2006, p. 349).

Um exemplo de projeto de arte locativa baseada em mapeamento é RealTime, de Ester Polak (Holanda), ${ }^{1}$ realizado de 28 de fevereiro a 30 de novembro de 2002. Como parte do projeto, os participantes foram convidados a andar pela cidade de Amsterdã, durante dois meses, munidos com aparelhos equipados com tecnologia de GPS. Os sinais de seus movimentos eram enviados para uma tela escura, na qual se materializaram em traços e linhas, as quais permitiram formar uma espécie de mapa de Amsterdã. Este, ao invés de registrar as ruas e avenidas, retratava os movimentos dos sujeitos envolvidos no projeto, revelando como 
tais sujeitos ocupam a cidade. Hemment acredita que esse tipo de projeto fornece

[...] um retrato visual evocativo da vida na cidade e um mapeamento colaborativo de base sobre como o espaço é utilizado, oferecendo uma alternativa em relação à perspectiva de cima para baixo da cartografia convencional (2006, p. 350).

Figura 1 - Mapa de Amsterdã produzido como resultado do projeto de arte locativa Real Time

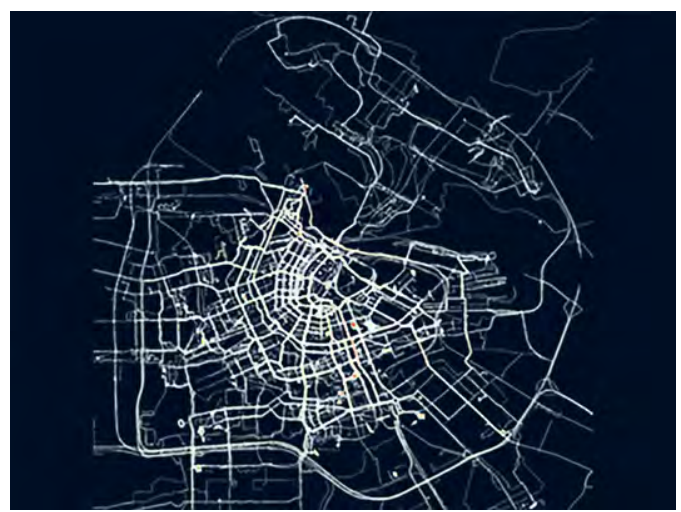

Fonte: disponível em: <https://waag.org/en/project/amsterdam-realtimes.

Projetos de geoanotação, por sua vez, pressupõem que certos dados digitais se tornem acessíveis apenas a partir de dados anexados anteriormente a determinados locais físicos. Em poucos termos, para acessar dados de projetos artísticos de geoanotação, é necessário literalmente se deslocar até os locais onde tais dados estão disponíveis. Antes da tecnologia de GPS, esses dados eram disponibilizados em suportes impressos, como cartazes, bilhetes, imagens, entre outros. Após a popularização do GPS e dos aparelhos móveis de última geração, esses dados passaram a ser disponibili- zados e acessados diretamente por meio dos aplicativos ${ }^{2}$ baixados nos próprios aparelhos, com base em coordenadas exatas de latitude e longitude, os quais frequentemente lançam mão também de tecnologia de realidade aumentada.

O projeto de geoanotação canadense Murmur ${ }^{3}$ é anterior à popularização do GPS e permite que os sujeitos participantes ouçam histórias e anedotas sobre certos locais específicos em algumas cidades selecionadas para o projeto. Em 2003, quando iniciou, havia pontos de geoanotação disponíveis apenas em Toronto, mas, no mesmo ano, também foram colocados pontos de acesso em Vancouver e Montreal. Nos últimos anos, o projeto acabou se expandindo para Calgary, ainda no Canadá, San Jose, na Califórnia, Edimburgo, na Escócia, Dublin, na Irlanda, e Geelong, na Austrália. Basicamente, os responsáveis pelo projeto gravam memórias, histórias pessoais e anedotas sobre certos locais específicos onde o projeto está disponível. Em cada um desses locais, é inserido um sinal impresso [murmur] com um número de telefone, o qual pode ser chamado por qualquer pessoa que esteja naquele local com um telefone móvel. Dessa forma, é possível realizar a experiência de estar no exato local onde a história narrada através do telefone de fato ocorreu, embora também seja possível ligar a partir de outros locais, desde que já se esteja de posse do número. 
Figura 2 - Foto de um participante do projeto Murmur em frente a um ponto de anotação

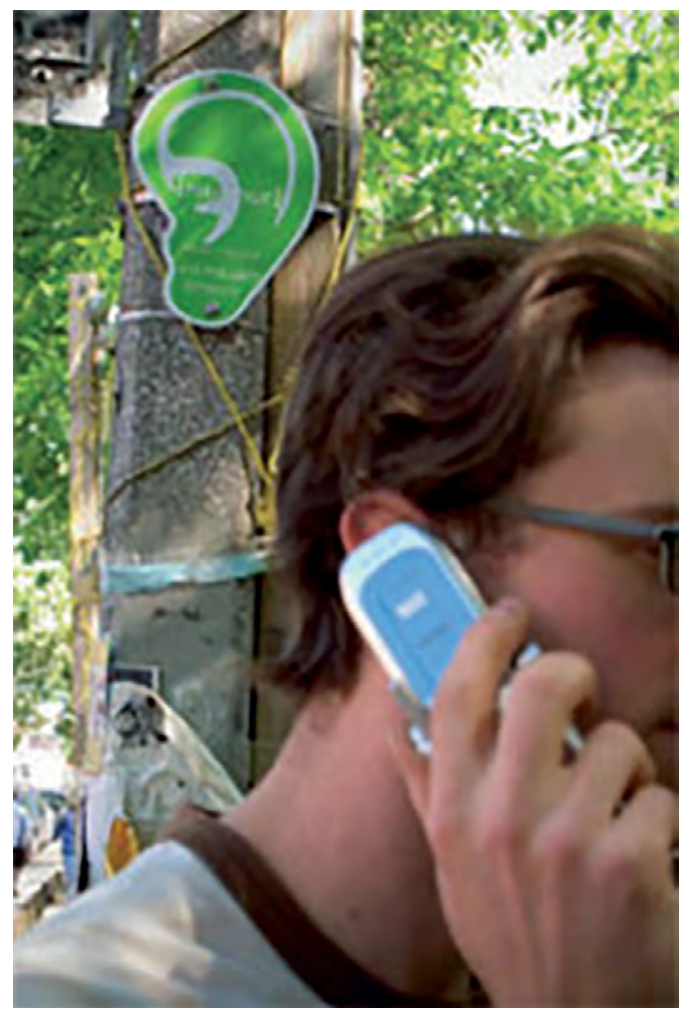

Fonte: disponível em: <http://murmurtoronto.ca/about. $\mathrm{php} />$.

Por fim, projetos ambulantes (de mobilidade) se caracterizam por dispensar qualquer representação baseada em telas de dispositivos ou em galerias, envolvendo, acima de tudo, o movimento, a deriva e o deslocamento, geralmente em ambientes urbanos. Nesse sentido, tais projetos se aproximam, de certo modo, dos projetos de geoanotação, deles se diferenciando pelo fato de não pressuporem, necessariamente, anotações em determinados locais ou em coorde- nadas específicas. Há muitos projetos dessa natureza, alguns de caráter mais exploratório (pressupondo apenas uma interação densa com os lugares percorridos), outros de caráter mais criativo ou produtivo (pressupondo que os participantes produzam ou criem algo ao longo da jornada $)^{4}$ e outros, ainda, de caráter mais social ou relacional (pressupondo apenas uma interação diferenciada entre os participantes). Esse último tipo de projeto frequentemente se assemelha, em seu formato, aos flash mobs ou, em alguns casos, aos smart mobs, conforme os compreende o teórico Howard Rheingold (2008, p. 226), ${ }^{5}$ visto que ensejam, além de uma intencionalidade puramente social ou estética, intenções de cunho político. Em 2002, por exemplo, o grupo alemão LIGNA (liderado pelos artistas de performance Ole Frahm, Michael Hueners e Torsten Michaelsen) executou, em algumas estações de trem alemãs, a performance Radio Ballet, ${ }^{6}$ sendo que um dos objetivos do grupo era subverter certas práticas de controle daqueles espaços. Conforme descrição no blog do grupo,

[...] cerca de 500 participantes - ouvintes de rádio comuns e não dançarinos ou atores - foram convidados a entrar na estação equipados com rádios e fones de ouvido baratos e portáteis. Com esses dispositivos, eles eram capazes de ouvir um programa de rádio que consistia de uma coreografia sugerindo gestos permitidos e proibidos (pedir esmola, sentar ou deitar no chão etc.). Essas sugestões foram interrompidas por reflexões sobre o espaço público e sobre o próprio Rádio ballet. ${ }^{7}$ 
Vários desses projetos envolvem práticas de leitura, escrita e audição de textos verbais, os quais, não raro, são dotados de algum grau de literariedade, o que levou alguns teóricos da literatura digital a considerá-los como um tipo ou um subgênero da literatura eletrônica ou digital. Ao discutir alguns projetos de "narrativas locativas", N. Kahterine Hayles, por exemplo, defende a inclusão desses projetos no campo da literatura digital, pois, segundo a pesquisadora,

[...] assim como o limite entre jogos de computador e literatura eletrônica é, na melhor das hipóteses, móvel, geralmente, trata-se mais de uma questão da tradição crítica a partir da qual as obras estão sendo discutidas do que de algo intrínseco às próprias obras (2008, p. 12).

Devido à impossibilidade de fixar características imanentes a obras de arte digital ou de literatura eletrônica que lhes assegurem a classificação em tipologias estáveis, Noah Wardrip-Fruin chegou a sugerir que a literatura digital seja compreendida como parte do espectro mais amplo da arte digital:

[...] a arte digital é a categoria mais ampla da qual a "literatura digital" é uma parte. Ela abrange todas as artes que demandam computação digital, não apenas as artes literárias (2010 apud CORREA-DÍAZ, 2016, p. 15).

Hayles situa sua própria reflexão no campo da literatura eletrônica e, assim sendo, em seu Eletronic literature: new horizons for the literary (2008), considera projetos de arte locativa envolvendo textos verbais como uma categoria da literatura eletrônica, a qual ela denomi- na de narrativas locativas. Nessa categoria, são enquadrados, além do projeto Murmur, também outros projetos de geoanotação, como Uncle Roy all around you ${ }^{8}$ e alguns projetos de experiência de realidade virtual, parte do programa de realidade virtual $C A V E$, criado e liderado por Robert Coover. Nesses últimos, para interagir com as obras, o sujeito deve utilizar óculos de realidade virtual que o teletransportam para um espaço tridimensional.

Como alerta Adriana de Souza e Silva (2013, p. 46), após a popularização de aparelhos de celular com GPS, principalmente depois de 2008, práticas de fruição, escrita e leitura com base em geolocalização vêm cada vez mais se deslocando do âmbito propriamente artístico na direção do âmbito popular e comercial. Ao se referir aos projetos de arte locativa anteriores a esse período, a pesquisadora afirma que eles foram importantes para as primeiras reflexões sobre como nós lemos e escrevemos os espaços urbanos, muito embora tenham ficado circunscritos a números muito pequenos de participantes e tenham apresentado restrições, tais como a necessidade de se estar em locais muito específicos (como Londres, Nova Iorque, Toronto, Leipzig, etc.) para poder realizar a experiência. Com a popularização dos aplicativos que incluem tecnologia de geolocalização entre suas funcionalidades, experiências de geoanotação passaram a se tornar tão corriqueiras nos últimos anos que, na opinião de Souza e Silva, estão trans- 
formando a sociabilidade dos sujeitos contemporâneos. Por outro 1

[...] dentre a miríade de novos aplicativos agora disponíveis para smartphones, alguns são um legado direto dos primeiros projetos de anotação com mobilidade (2013, p. 46).

McCullough, entre outros pesquisadores, acredita que as transformações desencadeadas pelas mídias locativas vêm promovendo uma verdadeira mudança de paradigma quanto ao modo como o sujeito contemporâneo experimenta $o$ mundo, a qual pode ser expressa como uma mudança da computação incorpórea (o velho paradigma) em direção à computação ubíqua (o novo paradigma):

Ao invés de um grande universo incorpóreo para ser explorado através dos óculos de uma tela de desktop [...], o novo paradigma midiático da computação ubíqua traz as coisas de volta à multiplicidade bagunçada do nível das ruas (2006, p. 26).

De fato, muitas teorizações sobre o universo digital, antes das tecnologias móveis, enfatizavam uma separação radical entre o mundo físico - corpóreo, material e limitado - e o ciberespaço, definido, frequentemente, como uma espécie de second life, imaterial, incorpóreo, virtual e praticamente ilimitado. Uma das principais consequências do uso intensificado das mídias locativas, portanto, é a hibridação ou o borramento das fronteiras entre o espaço digital da internet e o espaço físico do mundo habitado por nossos corpos. André Lemos denomina de território informacional esse novo espaço híbrido, o qual pode ser descrito a partir de "[...] áreas de controle do fluxo informacional digital em uma zona de intersecção entre o ciberespaço e o espaço urbano" (2007, p. 14).

Uma das principais consequências do território informacional para o âmbito da leitura e da escrita é o fato de que, como destaca Adriana de Souza e Silva, o uso massivo de aplicativos com geolocalização, nos últimos anos, tem estimulado uma produção cada vez mais intensa de formas textuais baseadas em localidade, as quais vêm transformando o espaço urbano em

[...] uma espécie de palimpsesto, contendo inúmeras camadas de texto em uma mesma superfície (urbana), gerando muitas camadas de sentido (SOUZA E SILVA, 2013, p. 34).

O palimpsesto é, originalmente,

[...] um pergaminho cuja primeira inscrição foi raspada para se traçar outra, que não a esconde de fato, de modo que se pode lê-la por transparência, o antigo sob o novo (GENETTE, 2010, p. 8).

Hoje, é utilizado para designar qualquer texto que se sobrepõe "[...] a outro que ele não dissimula completamente, mas deixa ver por transparência" (GENETTE, 2010, p. 144). No caso dos textos produzidos com tecnologia de geolocalização, o palimpsesto é uma excelente metáfora para caracterizar o acúmulo de textos verbais e imagéticos que se sobrepõem continuamente uns aos outros, na medida em que os usuários de aplicativos são convocados a deixar suas próprias avaliações, críticas, resenhas, ícones - enfim, uma miríade de possibilidades textuais e imagéticas - sobre as coordenadas designadas. 
Como exemplo desse fenômeno, pode-se citar, entre outros, a utilização dos aplicativos com tecnologia de localização e de reconhecimento de imagem produzidos pela empresa Google, os quais permitem ler textos que se sobrepõem sobre imagens de objetos ou de lugares, bastando, para tanto, apenas fazer uma foto desses objetos ou lugares com o próprio aparelho. Um desses aplicativos, $o$ Goggle Goggles, chegou a ser utilizado, em 2011, pelo Metropolitan Museum of Art, como suporte para informações sobre as suas obras. Thomas P. Campbell, diretor do museu à época em que essa mídia foi implantada, referiu-se da seguinte maneira às suas possiblidades:

Você já olhou para uma obra de arte - em um pôster, em um livro, em um cartaz ou mesmo em uma das galerias do Metropolitan Museum of Art - e simplesmente ficou com vontade de saber mais sobre ela? Agora você pode. Estou feliz de anunciar uma nova colaboração com o Google que permitirá que você faça uma foto de uma obra com seu aparelho móvel e se conecte diretamente com as informações sobre ela em metmuseum.org (CAMPBELL, 2011).

Em 2017, o aplicativo foi substituído pelo Google Lens, que, além de fazer tudo o que já fazia o Google Goggles, também é capaz de conectar o aparelho à internet através da imagem de código de barras, fornecer informações sobre espécies de plantas, entre outros, bastando, para tanto, o usuário utilizar a câmera do seu dispositivo móvel.

Outros aplicativos, como o Yelp, ${ }^{9}$ permitem não apenas a leitura de objetos e locais a partir de coordenadas espaciais, mas também a escrita de textos, pelos próprios usuários, que serão agregados aos demais textos já disponíveis nos locais de anotação, contribuindo, dessa forma, para aumentar ainda mais as camadas textuais que formam os palimpsestos a que se refere Souza e Silva. O Yelp foi criado, em 2014, para ajudar as pessoas a encontrar estabelecimentos próximos, como consultórios de dentistas, oficinas e salões de beleza; depois, além de ter ampliado o escopo de estabelecimentos acessíveis, esse aplicativo também permite que cada usuário deixe, por escrito, uma avaliação do estabelecimento buscado, a qual pode ser lida, compartilhada, replicada e enviada por outros usuários, o que acaba transformando-o também em uma rede social.

\section{Arquitetura Móvel, de Karolina Ziulkosky}

A artista brasileira Karolina Ziulkosky desenvolveu, em 2014, o aplicativo Arquitetura Móvel, que pode ser classificado como um projeto de arte locativa com geoanotação através de GPS e realidade aumentada. Segundo informações na página eletrônica destinada à divulgação do trabalho, ${ }^{10}$ esse projeto foi motivado pelo fato de a artista ter percebido a ausência de um local ou de um monumento que reconhecidamente representasse a cidade de São Paulo, como ocorre, por exemplo, com Paris (a Torre Eiffel) e o Rio de Janeiro (Cristo Redentor), entre outras cidades. Assim, 
Ziulkosky decidiu desenvolver um aplicativo que permitisse interferir na paisagem urbana de São Paulo, inserindo, com tecnologia de realidade aumentada, prédios famosos de diferentes lugares do mundo na Avenida Paulista.

$\mathrm{O}$ aplicativo pode ser encontrado através de buscas em locais virtuais especializados em arte digital. O Museu de Imagem e do Som de São Paulo, entre outras iniciativas, mantém um laboratório, o LabMis, para incentivar artistas que trabalham com arte e tecnologia. A instituição investe em quatro projetos por ano e, dentre os trabalhos realizados em 2014, consta o aplicativo de Karolina Ziulkoski. O trabalho foi disponibilizado já em 2014 com download gratuito. Porém, só aparece disponível para $d o$ wnload quando se está fisicamente em São Paulo e, além disso, só poderá ser baixado por portadores de smartphones ou tablets da Apple (iPads), pois foi desenvolvido para rodar exclusivamente com o software iOS.

$\mathrm{O}$ aplicativo ainda estava ativo para download em dezembro de 2016, quando foram realizadas as atividades de interação cujos dados são utilizados como base para as reflexões apresentadas neste artigo. No endereço para instalação, que contém as informações do aplicativo, bem como no vídeo tutorial para orientar o seu uso, o número de downloads realizados não é mencionado, tampouco há nota para o aplicativo, pois, segundo informação na página, não houve o número mínimo de comentários necessários para gerar uma média. A página informa que a última atualização do aplicativo foi feita em 2014.

Figura 3 - Excerto visual do endereço de hospedagem do aplicativo Arquitetura Móvel

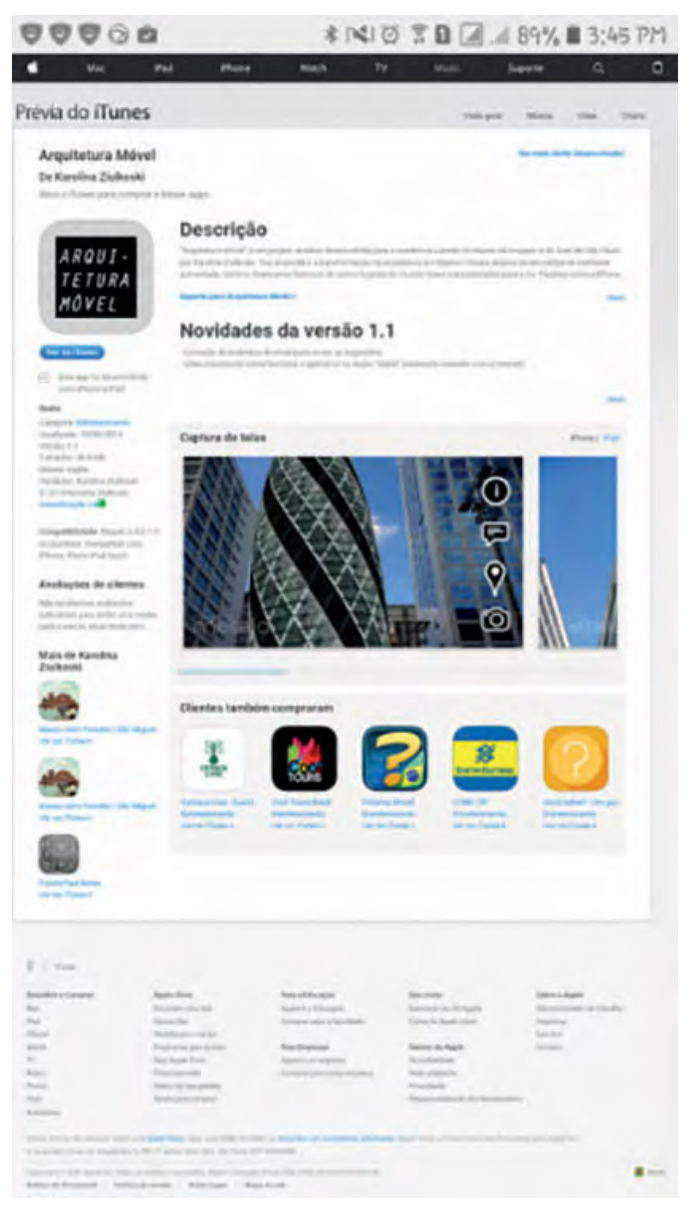

Fonte: dos autores.

A artista percebeu que diversos prédios centenários e importantes para a memória da cidade, na região em torno da Avenida Paulista, em São Paulo, vêm sendo substituídos, nos últimos anos, 
por grandes prédios que se assemelham, segundo ela, aos que ocupam centros financeiros mundiais. Para chamar a atenção sobre as alterações na paisagem urbana, ela teve a ideia de criar um aplicativo em que edifícios famosos de outras cidades aparecem se sobrepondo aos prédios mais antigos da avenida. Dessa forma, os novos olhares, a partir do aplicativo, estimulariam reflexões e interações sobre a padronização dos projetos arquitetônicos contemporâneos.

A experiência oferece a possibilidade de olhar, ao mesmo tempo, para a paisagem real, sem a mediação do aparelho, e para a paisagem imaginada pela artista, através do aparelho, caracterizando-se, dessa forma, como um tipo de palimpsesto. Esse duplo olhar pretende causar estranhamento em relação a uma paisagem urbana já conhecida, mas, segundo a artista, também serve para gerar discussões que busquem proteger e valorizar a memória urbana e o patrimônio arquitetônico. Nesse sentido, Arquitetura Móvel dialoga, de certa forma, com o conceito Playable City, ${ }^{11}$ (cidade jogável), que tem inspirado a produção de boa parte dos produtos e serviços recentes baseados na mobilidade.

A ideia de cidade jogável é utilizada de forma cada vez mais frequente para descrever o potencial que a infraestrutura das cidades oferece para as mídias locativas. Ampliando a ideia mais restritiva de simplesmente estar apto a acessar informações em qualquer ponto da cidade, o novo conceito sugere uma relação dinâmica e interativa entre as mídias locativas, o espaço urbano e os sujeitos. Dessa forma, a infraestrutura da cidade passa a ser vista não apenas como potencial para a inserção de pontos ou coordenadas, mas, sim, como um verdadeiro palco para troca de experiências e reconfigurações. Objetos, hábitos e locais se transformam, dessa forma, em pontos-chave para os produtos e os serviços das mídias locativas. A expressão "cidade jogável”, em última análise, revela a busca por tornar o trinômio tecnologia, localização e mobilidade cada vez mais presente nos deslocamentos urbanos dos sujeitos.

Uma das primeiras iniciativas a empregar esse termo foram as maratonas Playable City, que ocorrem em várias cidades do mundo, inclusive do Brasil. Elas reúnem artistas e designers voltados a desenvolver obras que explorem uma "abertura" na gestão da cidade, de modo a melhorar a vida social, cultural e econômica dos habitantes. A iniciativa pretende encontrar, por intermédio da arte, formas diversas pelas quais a tecnologia possa promover o desenvolvimento das cidades e contribuir para a qualidade de vida em centros urbanos. O prêmio pretende oferecer, a artistas e criadores de mídia do mundo, a oportunidade de realizar algo utilizando tecnologias criativamente, com surpresas e desafios, e engajando as pessoas na exploração da "cidade jogável". Forçando os limites e encorajando experimentações, esse prêmio internacional se situa na intersecção entre tecnologia e cultura. 
$\mathrm{Na}$ tela de apresentação de Arquitetura Móvel, é possível ler a proposta do projeto, conforme a reprodução a seguir:

Esse aplicativo é um projeto artístico onde centros financeiros famosos são 'transplantados' para a Av. Paulista através da tecnologia de realidade aumentada. O estranhamento de tornar um edifício em um objeto móvel é ponto de partida para discussões a respeito dos rumos urbanísticos da segunda maior metrópole das Américas. Nada do que é mostrado aqui deve ser levado como uma sugestão para o local. Apenas para discussão. Agora é só COMEÇAR. Para saber mais, vá à seção SOBRE (ZIULKOSKI, 2014, p. 1).

Figura 4 - Excerto visual da tela de início do aplicativo Arquitetura Móvel

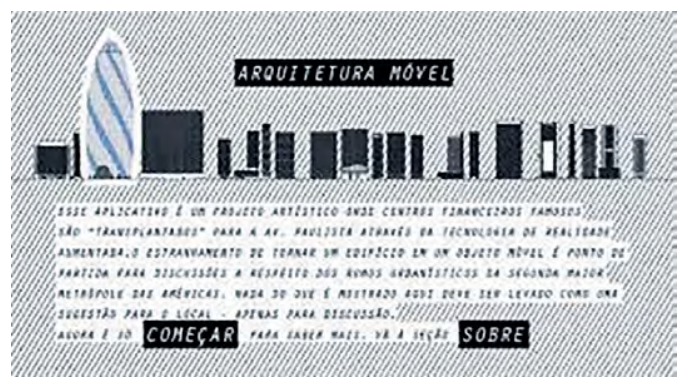

Fonte: dos autores.

A partir desse texto inicial, basta clicar em COMEÇAR para acompanhar a imagem do local onde se está situado, tal qual quando é acionada a máquina fotográfica do aparelho celular. Na Figura 5, é possível ver a captura da tela no momento em que iniciou a experiência prática de interação com o aplicativo para os fins desta análise.
Figura 5 - Excerto visual de imagem do ambiente intermediado pelo aplicativo Arquitetura Móvel

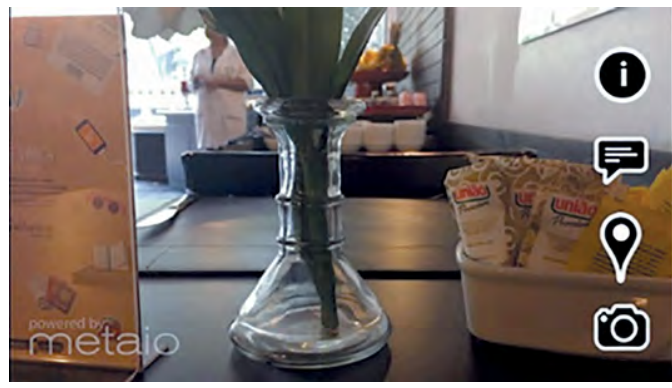

Fonte: dos autores.

$\mathrm{Na}$ lateral direita da tela, estão disponíveis quatro ícones, que permitem, ao utilizador, realizar diferentes ações: o primeiro ícone, posicionado na parte superior direita, fornece informações; o segundo permite que o utilizador insira suas próprias impressões, por escrito, o que aproxima o aplicativo do conceito de narrativa locativa, proposto por $\mathrm{N}$. Katherine Hayles; o terceiro serve para localização; e o último, para capturar imagens.

Ao tocar no ícone de localização, o utilizador abre um mapa, que apresenta os locais-chave propostos pela artista para observar modificações na paisagem urbana bem como o local onde se encontra, além de oferecer informações sobre o trajeto a ser percorrido para chegar a cada local onde será possível usufruir da experiência, conforme a Figura 6. 
Figura 6 - Excerto visual da tela de localização do aplicativo Arquitetura Móvel

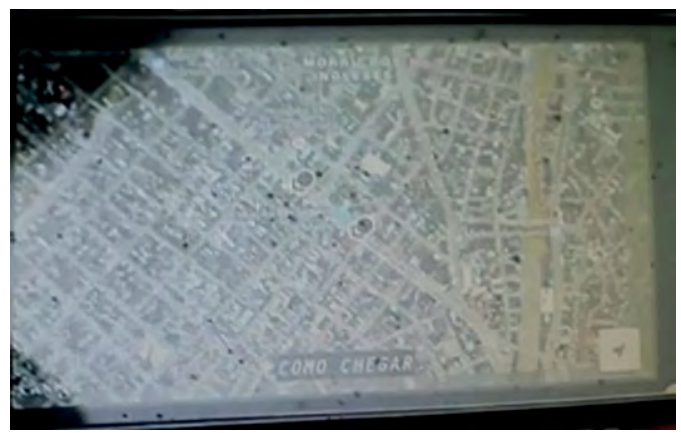

Fonte: dos autores.

Após escolher um dos pontos apresentados no aplicativo, o usuário deve se dirigir a ele para se posicionar no local exato determinado pela artista. Esses pontos estão situados em frente ao local onde o novo prédio será inserido, mais precisamente, do outro lado da rua, para ampliar seu campo de visão. O ponto destacado no mapa a seguir (Figura 7) mostra o local onde o utilizador deve estar, e não a posição exata do prédio que será coberto pela imagem inserida por meio de realidade aumentada.

Figura 7 - Excerto visual da tela de descrição dos pontos de experiência do aplicativo Arquitetura Móvel

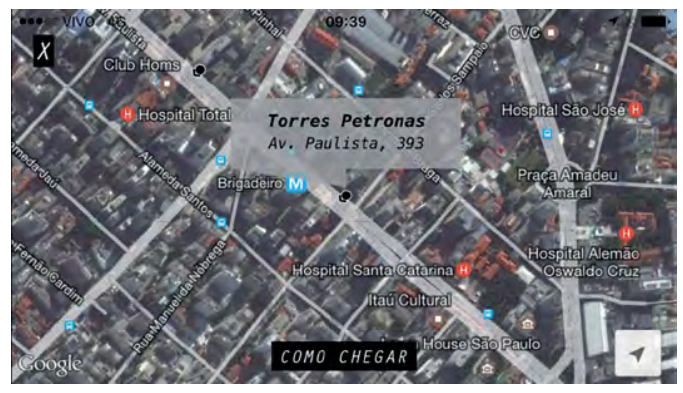

Fonte: dos autores.
Ao tocar em 'COMO CHEGAR', que aparece na parte central inferior da Figura 7 , uma tela com as possibilidades de trajetos se abre. $\mathrm{O}$ utilizador poderá clicar em qualquer uma das cinco opções disponíveis (carro, metrô, a pé, de ônibus ou de bicicleta) para receber informações sobre o trajeto a partir de onde se encontra, até o ponto selecionado. Na tela, também aparece o tempo aproximado necessário para realizar cada uma das modalidades de deslocamento. $\mathrm{Na}$ experiência realizada para esta análise, foi capturada a imagem da tela que descrevia como seria o deslocamento de carro até as Torres Petronas. A posição de saída é demarcada pelo balão vermelho, conforme a Figura 8.

Figura 8 - Excerto visual da tela de trajetos do aplicativo Arquitetura Móvel

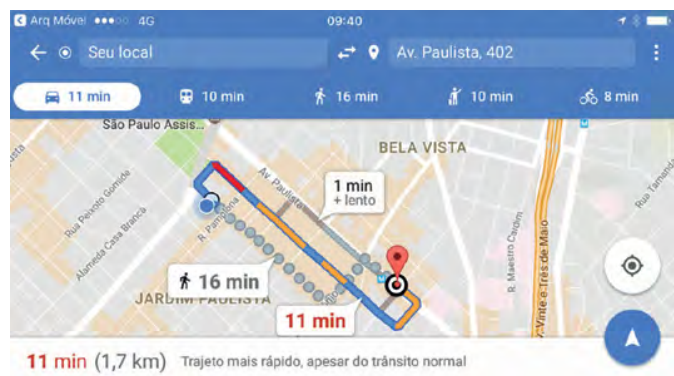

Fonte: dos autores.

Já posicionado, o utilizador deverá observar a paisagem através da tela do celular: assim que apontar o smartphone na direção do prédio selecionado, este será substituído pelo prédio imaginário proposto pela artista, criando-se, dessa forma, uma espécie de palimpsesto, para 
utilizar o termo proposto por Adriana de Souza e Silva. Movimentando o dispositivo, o usuário poderá observar toda a extensão da paisagem urbana que cerca a inserção, do chão ao céu, de um lado ao outro, sem que o prédio inserido saia da tela. Na interação realizada com o aplicativo para esta análise, após capturar a imagem da Igreja São Luís nas coordenadas fornecidas pelo aplicativo, ocorreu a inserção, por realidade aumentada, da Gherkin Tower, que substituiu a imagem original. Nas Figuras 9 e 10, é possível visualizar a captura de ambas as imagens.

Figura 9 - Excerto visual de imagem do endereço Avenida Paulista, 2878

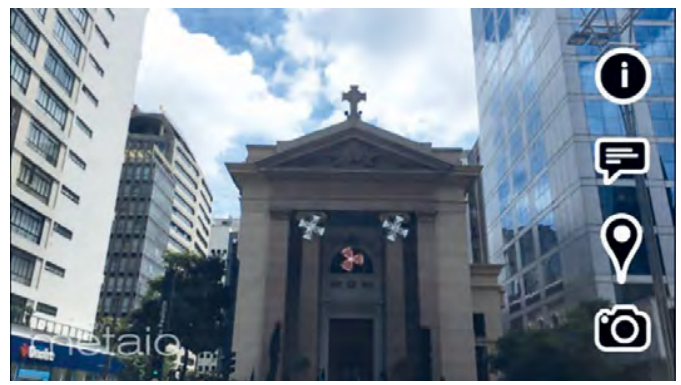

Fonte: dos autores.

Figura 10 - Excerto visual de imagem do mesmo endereço após a ação do aplicativo através de realidade aumentada

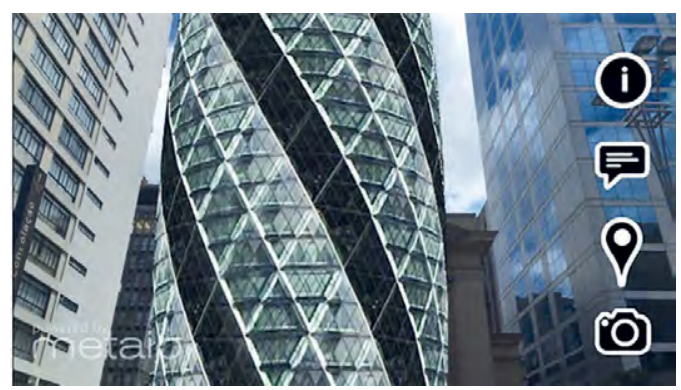

Fonte: dos autores.
Além de promover uma leitura de textos sobrepostos através de realidade aumentada, o aplicativo Arquitetura Móvel também permite que o utilizador produza e divulgue seus próprios textos, verbais e/ou icônicos. Para tanto, deve-se acessar o ícone em forma de um balão de texto disponível na tela principal. Ao clicar no balão, duas opções se apresentam: DESENHE ou ESCREVA (Figura 11).

Figura 11 - Excerto visual de imagem do vídeo de divulgação que mostra a tela para produção de conteúdo

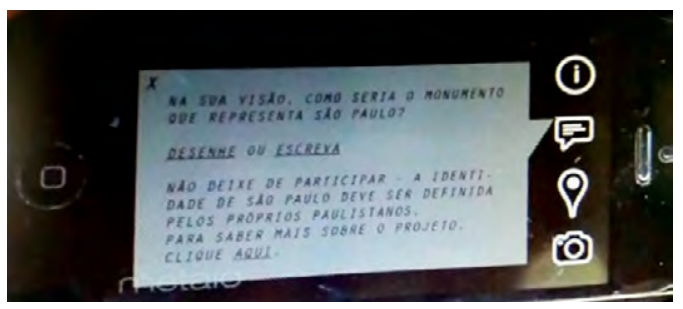

Fonte: dos autores.

Se o utilizador clicar em ESCREVA, deverá escolher uma das opções apresentadas na tela: Facebook, Twitter ou e-mail - todas coordenadas pela artista (Figura 12).

Figura 12 - Excerto visual do vídeo de divulgação mostrando as opções de compartiIhamento oferecidas pelo aplicativo

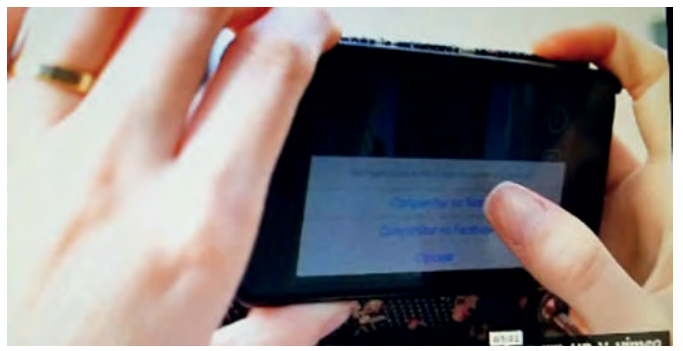

Fonte: dos autores. 
Em nenhum dos casos, o utilizador permanece anônimo, pois cada uma dessas postagens será originada ou de sua página pessoal em uma das redes sociais referidas no aplicativo (Facebook, Twitter), ou a partir do seu correio eletrônico. Caso opte por DESENHE, um menu com paleta de cores e ferramentas para traços permite a criação de uma imagem realizada com os dedos diretamente na tela, conforme ilustrado na Figura 13.

Figura 13 - Excerto visual do vídeo de divulgação que mostra as possibilidades de produção gráfica de imagem a partir do aplicativo

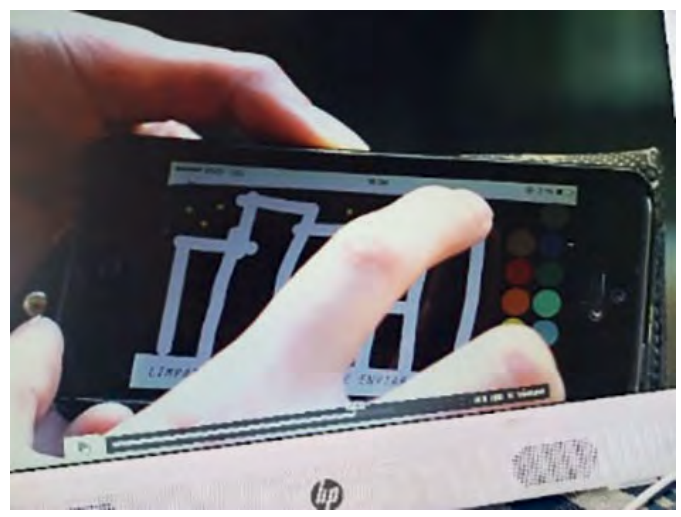

Fonte: dos autores.

A imagem produzida dentro do aplicativo também poderá ser compartilhada nos mesmos canais oferecidos para os textos verbais. No ícone representado por uma máquina fotográfica, também na tela principal, é possível capturar a imagem que está sendo visualizada pelo utilizador. A imagem poderá ser salva em álbum pessoal, compartilhada em redes sociais ou enviada por e-mail.
Segundo Arlindo Machado (2007), a arte, quando ocorre em meio ao ambiente tecnológico, estaria propondo algo distinto e inesperado em relação à função da própria tecnologia utilizada como suporte; a perspectiva artística seria, de certo modo, desviante, afastando a tecnologia do seu próprio processo tecnológico para desnudar seus procedimentos, explorá-los, subvertê-los, torná-los intencionados. É partir desse tipo de desvio de função ou vocação, portanto, que passamos a escutar o que a obra de arte, e não o objeto tecnológico, tem a nos dizer.

Nesse sentido, é possível afirmar que, poeticamente, Arquitetura Móvel subverte, de certa forma, a própria função do serviço de geolocalização, que é a localização precisa dos lugares procurados. Mais do que levar o utilizador aos locais determinados na Avenida Paulista, o aplicativo de Karolina Ziulkosky transforma a experiência objetiva com esses locais em uma experiência subjetiva e poética. Em poucos termos, o serviço nos leva a verificar, pela tela, algo que não está lá fisicamente: localiza um prédio de outro ponto naquele ponto. É em seu "erro", portanto, ou no desvio da prática dessa tecnologia, na deslocalização, que a poética dessa obra acontece. Assim, a informação precisa e utilitária, que é normalmente fornecida pelos serviços de localização em aplicativos, transforma-se, em Arquitetura Móvel, em informação poética, sugestiva, subjetiva; e o palimpsesto, ao invés de se traduzir em 
meras camadas de textos sobrepostos, transforma-se em camadas de textos que se desafiam uns aos outros, criando sentidos múltiplos e abertos.

\section{New ways of reading and writing in the mobility era: reflections on locative arts}

\begin{abstract}
In this article, we propose a reflection on the new ways of reading and writing that emerge in the age of mobility, taking as object of analysis some artistic and literary projects carried out with locative media, with emphasis on the work Mobile Architecture, by the Brazilian artist Karolina Ziulkosky. The analyzes are based on a bibliographical research, on the one hand, and, on the other hand, on an experience of interaction with the work Mobile Architecture, during 4 days, from December 8 to 12, 2016, at Avenida Paulista, in São Paulo, Brazil. In order to achieve its goals, the article is structured in three sections. After a brief introduction, we present the theoretical concepts underlying the discussions and, in the sequence, we present the analysis of the work Mobile Architecture. Some of the main researchers we draw on as theoretical references for the analyzes are Drew Hemment, André Lemos, Adriana de Souza e Silva, Marc Tuters, Kazys Varnelis, Howard Rheingold, Kahterine Hayles, Malcolm McCullough.
\end{abstract}

Keywords: Locative narratives. Locative art. Locative media. Mobile Architecture.

\section{Notas}

1 Disponível em: <https://waag.org/en/project/ amsterdam-realtime $>$. Acesso em: 23 jul. 2017.

2 Os aplicativos são programas para computador desenvolvidos para cumprir funções específicas; como utilizam menos dados, executam o trabalho com rapidez e facilidade. Apesar de desenvolvidos para qualquer computador, convencionou-se usar o nome 'aplicativo', ou app, para os programas disponíveis para download em smartphones e tablets. Várias lojas virtuais vendem ou disponibilizam gratuitamente os aplicativos, como Google Play, Apple Store, Windows Phone Store, entre outras. Alguns deles já vêm pré-instalados no dispositivo, outros devem ser selecionados e baixados das lojas.

3 Disponível em: <http://murmurtoronto.ca/ about.php/>. Acesso em: 23 jul. 2017.

4 Um exemplo desse tipo de projeto é .walk, do holandês Wilfried Houjebek. Informações sobre esse projeto estão disponíveis em: $<$ https://transmediale.de/content/walk>.

5 Howard Rheingold cunhou o termo smart mobs para caracterizar grupos que organizam e coordenam ações políticas coletivas através de tecnologia móvel.

6 Disponível em: <http://ligna.blogspot.com. br/2009/12/radio-ballet.html>. Acesso em: 23 jul. 2017.

7 Disponível em: <http://ligna.blogspot.com. br/2009/12/radio-ballet.html>. Acesso em: 23 jul. 2017.

8 Disponível em: <http://www.blasttheory. co.uk/projects/uncle-roy-all-around-you/>. Acesso em: 23 jul. 2017.

9 Disponível em: <https://www.yelp.com/ about>. Acesso em: 23 jul. 2017.

10 Disponível em: <http://www.karolinaziulkoski.com/filter/Apps/Arquitetura-Movel>. Acesso em: 23 jul. 2017.

11 Disponível em: <https://www.playablecity. com>. Acesso em: 23 jul. 2017. 


\section{Referências}

CAMPBELL, Thomas P. Google Goggles. 2011. Disponível em: <http://www.metmuseum.org/blogs/now-at-the-met/from-the-director/2011/google-goggles>. Acesso em: 23 jul. 2017.

CORREA-DÍAZ, Luis. Una introducción. In: CORREA-DÍAZ, Luis; WEINTRAUB, Scott (Ed.). Poesía y poéticas digitales / electrónicas / tecnos / new-media en América Latina: definiciones y exploraciones. Bogotá: Ediciones Universidad Central, 2016. p. 14-20.

GENETTE, Gérard. Palimpsestos a literatura de segunda mão. Belo Horizonte: Viva Voz, 2010.

HAYLES, Nancy Katherine. Eletronic literature: new horizons for the literary. Indiana: University of Notre Dame, 2008.

HEMMENT, Drew. Locative Arts. Leonardo, MIT Press, Cambridge, Massachusetts, EUA, v. 39, n. 4, p. 348-355, 2006.

MCCULLOUGH, Malcolm. On the Urbanism of Locative Media. Places, University of California, California, EUA, v. 18, n. 2, p. 26-29, 2006.

LEMOS, André. Mídia locativa e territórios informacionais. In: ARANTES, Priscila; SANTAELLA, Lúcia (Ed.). Estéticas tecnológicas: novos modos de sentir. São Paulo: Editora PUC-SP, 2007. p. 95-101.

MACHADO, Arlindo. Arte e mídia. Rio de Janeiro: Zahar, 2007.

RHEINGOLD, Howard. Mobile media and political collective action. In: KATZ, James E. (Ed.). Handbook of mobile communication studies. Cambridge; London: The MIT Press, 2008. p. 225-240.

RUEB, Terry. Restless. Locative media as generative displacement. Leonardo, MIT Press, Cambridge, Massachusetts, EUA, v. 21, n. 1, p. 220-234, 2004.
SOUZA E SILVA, Adriana. Mobile narratives: reading and writing urban space with location-based-technologies. In: HAYLES, Nancy Katherine; PRESSMAN, Jesica (Ed.). Comparative textual media: transforming the humanities in the postprint era. Minneapolis; London: University of Minnesota Press, 2013. p. 33-52.

TUTERS, Marc; VARNELIS, Kazys. Beyond locative media: giving shape to the internet of things. Leonardo, MIT Press, Cambridge, Massachusetts, EUA, v. 39, n. 4, p. 357-363, 2006.

ZIULKOSKI, Karolina. Aplicativo Arquitetura Móvel. 2014. Disponível em: $<$ https://itunes.apple.com/br/app/arquitetura-m\%C3\%B3vel/id913363226? $\mathrm{mt}=8>$. Acesso em: 19 set. 2014. 